\title{
Goodbye: an immigration story
}

\author{
Cite as: CMAJ 2019 March 4;191:E261-2. doi: 10.1503/cmaj.180933
}

CMAJ Podcasts: audio reading at https://soundcloud.com/cmajpodcasts/180933-enc

\begin{abstract}
n medical school, we learn about the pathophysiology of diseases. We learn the best test to order and the best medication for treatment. But we are not taught how to treat our patients' stories, the social factors that make it impossible for them to pay for that medication or get to the appointment for that diagnostic test. As a family medicine doctor, I am privileged to seek out these stories, to look for the complex and interwoven contexts in which my patients live. After I listen, I am left with the shared burden of trying to help my patients navigate these social factors - access to housing, medical insurance, documented immigration status - that so define their health. I
\end{abstract}

embrace their stories, and there are many of them that I could tell. But today I write to a patient who came to the United States looking for opportunity, and then left, pushed away by a country that did not care about her. I want her to know I cared.

The nurse stood in the doorway of the mobile health centre, squinting into the sunshine of the surrounding parking lot. She turned around and walked up the final step into the clinic, her petite frame still blocking the doorway. With a grin, she looked at me: "You'll never guess who's on her way!"

There were no more visits scheduled for the day, but patients often came whenever they could, sometimes hours after their scheduled appointment time. Often their transportation had been late, their job had kept them for overtime, or childcare had failed to arrive.

Today it was you, Ana.

Our nurse moved out of the door frame and I saw you, reaching out to me before you were even inside the clinic: "Doctora!" During the previous year, I had seen you frequently. Your blood pressure had spiked; you had had chest pain; we had discovered pulmonary hypertension and treated you, briefly, with medications obtained at lower prices from your home country. You had moved on from your job as a live-in nanny to sleeping in a church,

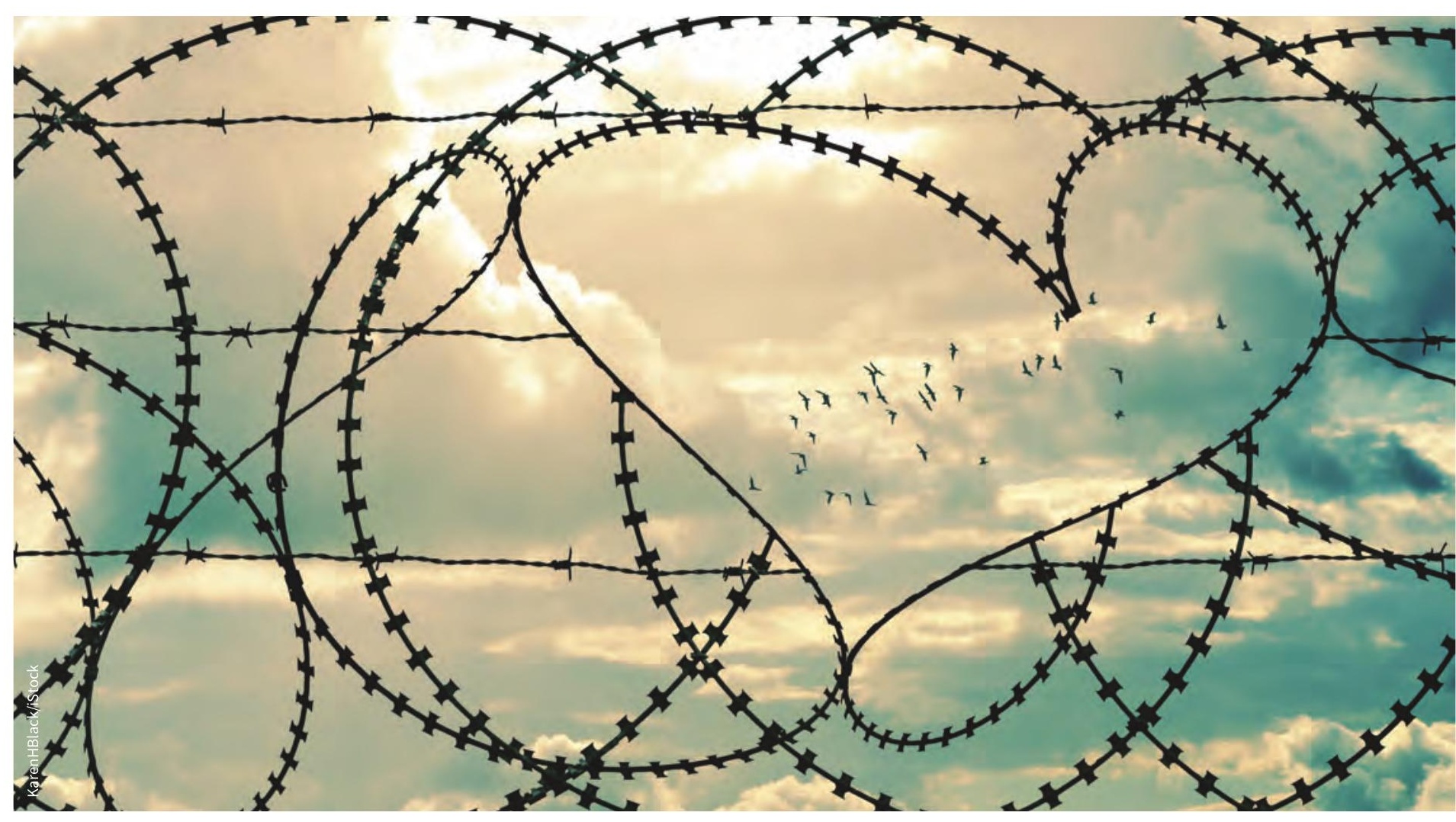


and you had learned how to navigate the bus system to get to the clinic. Even when your eyes looked at me and brimmed over, you smiled. You had no insurance and no documents giving you legal residency, so I had little to offer you. The cardiologist was too expensive. You could not afford the medications. I thought of you frequently at night, when I was trying to fall asleep; I knew how to treat the pathophysiology of your diseases but I could not treat the other social factors, which had so much power over your body and life.

One of our nurses had finally gone with you to the safety-net hospital in our city; this is a hospital tasked with seeing anyone who lives in our county, regardless of immigration status or medical insurance. To be seen there, though, you needed to get approved for a special card that showed you lived in our city and were poor. Your application for that card kept being denied.

After you were finally approved, I saw you less. The hospital was closer to the church where you were staying, and its pharmacy filled your prescriptions at a lower price. I had last heard from you a few months before. It was Labour Day and I was travelling. You were at the hospital pharmacy and wondering why it was closed. I told you that it was a holiday, and you laughed: "Ah, si!" You said you'd see me soon.
Today you came to tell us that you were leaving to go back to Honduras. You said you were tired of feeling indebted to the church where you slept, of having to fight for medical care, of having to use WhatsApp to see your children's faces. Today, there were no tears in your eyes. You pulled up your daughter on the screen of your phone, as she sat in her bedroom in Honduras, and showed her around the clinic. The nurse and I held the phone and waved at her: "Hola!" You hung up the call. I gave you scripts for all your medications, and we printed out your records.

You hugged me tightly and said goodbye, and I watched you turn, walk down the stairs, and away through the thick, moist air of the Miami afternoon. I thought about how I had gone into medicine with little understanding of how deeply intertwined my patients' stories would become with my own. Mostly, I wondered how you weren't angry at me and the privilege bestowed upon me by my birthplace. I commented to the nurse that you looked so happy that day, and she reminded me of the violence that haunts your country. I realized how impossible the so-called American dream must have seemed to you, to push you back across the borders you had previously spent months crossing on foot.

You might be surprised to know that I still think of you often, just as before. The nurse still turns to me at the end of many clinic days: "You'll never guess who's coming now!" And sometimes, I think it might be you. I think of you and I am angry that, even with the vast resources of the United States and its so-called melting pot of people, health care remains a privilege and not a right. It is because of this injustice that I write your story.

Being your doctor demanded more than treating the pathophysiology of your diseases. It required that I picked up the phone when you called, researched the most affordable medications, provided you with information about food banks. It was heartbreaking that this wasn't enough. I am still grateful for the days that you were my patient, confronting me with the realities that had dragged you far from home and then pulled you back. And so I continue to open the clinic door, ready to make your story a different one for the next patient.

\section{Sarah E. Stumbar MD MPH}

Department of Humanities, Health and Society, Herbert Wertheim College of Medicine, Florida International University, Miami, Fla.

This article has been peer reviewed.

This is a true story. Ana has given her consent for this story to be told.

Editor's note: This is the second part of Ana's story. Part 1 was published Nov. 6, 2017 at http:// www.cmaj.ca/content/189/44/E1366. 